The Social Determinants of Health as they relate to children and youth growing up with HIV infection in sub-Saharan Africa

Skovdal, Morten; Belton, Sara

Published in:

Children and Youth Services Review

DOI:

10.1016/j.childyouth.2014.03.024

Publication date:

2014

Document version

Peer reviewed version

Document license:

CC BY-NC-ND

Citation for published version (APA):

Skovdal, M., \& Belton, S. (2014). The Social Determinants of Health as they relate to children and youth growing up with HIV infection in sub-Saharan Africa. Children and Youth Services Review, 45, 1-8. https://doi.org/10.1016/j.childyouth.2014.03.024 
Introduction

\title{
The Social Determinants of Health as they relate to children and youth growing up with HIV infection in sub-Saharan Africa
}

\author{
Morten Skovdal ${ }^{\mathrm{a}, \mathrm{b}, *}$, Sara Belton ${ }^{\mathrm{c}}$ \\ ${ }^{a}$ Department of Public Health, University of Copenhagen, Copenhagen, Denmark \\ ${ }^{b}$ Department of Programme Policy and Quality, Save the Children, London, United Kingdom \\ ${ }^{c}$ Department of Social Psychology, London School of Economics and Political Science, United Kingdom
}

\section{A R T I C L E I N F O}

Available online 5 April 2014

\section{Keywords:}

Community engagement

Policy and practice implications

Children's lived experience

Child-focused care/family-centered care

\begin{abstract}
A B S T R A C T
There are concerns that current models of HIV service delivery pay insufficient attention to the struggles of children, their families and health services in managing the social factors that govern the health, development and psychosocial well-being of children and youth growing up with HIV in sub-Saharan Africa. The papers in this Special Issue offer some direction for how we can offer more holistic and integrated responses that accommodate a broader vision of children's needs and provide a strong rationale for developing a framework of Social Determinants of Health as they relate to children and youth living with HIV in subSaharan Africa. We argue that such a perspective has the potential to improve HIV treatment outcomes by cementing the need to i) understand, measure and respond to drivers of health, health inequities as well as barriers to development; ii) foster partnerships and inter-sectoral cooperation; iii) adopt child-, family- and community-centered approaches that are linked to broader care and support systems; and iv) develop a focused research agenda on Social Determinants of Health as they relate to children and youth living with HIV. Given that HIV is experienced, lived and managed within interpersonal relationships, overlapping and complex social structures and economic systems, we conclude that efforts to achieve an AIDS-free generation are most likely to be successful if they recognize and engage with the Social Determinants of Health as they relate to children and youth living with HIV.
\end{abstract}

(c) 2014 Elsevier Ltd. All rights reserved.

\section{Introduction}

The HIV response has been nothing but remarkable. Over the past decade we have witnessed a slow but steady decrease in HIV infections and a rapid scale up of antiretroviral therapy (ART). For example, from 2011 to 2012, it has been estimated that the number of people on ART in sub-Saharan Africa grew by one fifth to more than 7.5 million people, up from 50,000 a decade earlier (WHO, UNICEF and UNAIDS, 2013). This unprecedented scale-up of ART is believed to have averted 4.2 million deaths in low- and middle-income countries between 2002 and 2012 (ibid.). Progress has also been made in preventing HIV transmission. The scale-up of interventions preventing mother-to-child HIV transmission (PMTCT) is estimated to have prevented 800000 children from becoming newly infected between 2005 and 2012 (WHO et al., 2013). In light of current progress, UNICEF (2013), in its sixth stocktaking report on the response to HIV and AIDS among children in low- and middleincome countries, argues, given current knowledge, experience and

\footnotetext{
* Corresponding author at: Department of Public Health, University of Copenhagen, Øster Farimagsgade 5, 1014 Copenhagen, Denmark.

E-mail address: m.skovdal@gmail.com (M. Skovdal).
}

tools, that we are now within the remit of achieving an AIDS-free generation. ${ }^{1}$

However, despite these successes, many challenges remain. More people get infected with HIV every day than are getting access to lifesaving treatment (UNAIDS, 2013; WHO et al., 2013). In contexts where HIV infection, AIDS-related mortality and morbidity are on the decline, large groups of adults and children living with or affected by HIV continue to require care and support. Despite expanding domestic investments in HIV, 2012 saw no increase in international HIV assistance, leaving commitments to the global HIV response target short of approximately US\$ 4.1 billion (UNAIDS, 2013). Tolle et al. (2013) argue that progress to achieve an AIDS-free generation will carry a cost and call for increased funding. In addition to increasing funding commitments, there is a need for more targeted and strategic investment approaches to the HIV response (Schwartländer et al., 2011), including recognition of the community response to HIV (Campbell

\footnotetext{
${ }^{1}$ UNICEF (2013) defines an AIDS-free generation as a generation in which all children are born free of HIV and remain free from HIV through to adolescence. It also implies that children currently living with HIV have access to the necessary HIV services to remain alive and well.
} 
et al., 2013; Skovdal, Magutshwa-Zitha, Campbell, Nyamukapa, \& Gregson, 2013).

Certain key populations continue to be disproportionately affected, both when it comes to HIV acquisition and access to HIV services, fuelled by inequalities, stigma and discrimination (Silva-Santisteban et al., 2013). Children living in low- and middle-income countries, and diagnosed with HIV, for example, are nearly half as likely as adults to access to treatment. In 2012, only $34 \%$ of children under the age of 15 and in need of treatment received antiretroviral therapy compared to $64 \%$ of adults (UNICEF, 2013). These disparities can partly be explained by children's reliance on their caregivers to access HIV services (Skovdal, Campbell, Madanhire, Nyamukapa, \& Gregson, 2011) and the inadequacy of HIV services to address the clinical and social needs of children living with HIV (Mugglin et al., 2013). Even when children are initiated on ART, barriers such as poverty, the distance to the local clinic, side effects, stigma and discrimination, and lack of disclosure affect the ability of children and youth to adhere to their treatment regimen and result in 'loss to follow-up' (Braitstein et al., 2011; Campbell et al., 2012; Wachira, Middlestadt, Vreeman, \& Braitstein, 2012). While retention rates are generally high in the first 12 months of treatment, a number of studies highlight a gradual decline following that period, undermining viral suppression and increasing the risk of drug resistance (Barth et al., 2011). A recent review of HIV care and treatment programs in Kenya, Mozambique, Rwanda, and Tanzania found that retention rates for children, particularly for those very young, could be as low as $62 \%$ after 24 months in care (McNairy et al., 2013). Even when countries, like Rwanda, demonstrate high retention rates among children enrolled in national HIV care programs, younger children are identified as particularly vulnerable to loss to follow-up (Tene et al., 2013).

These challenges suggest a limit to the biomedical HIV response and that the vision of an AIDS-free generation is still some distance away. In response, and with an emphasis on work reporting on children's experiences of growing up with HIV, we convened, in partnership with Save the Children, a two-day conference at the London School of Economics and Political Science in March 2013 to gather 'knowledge, experience and tools' from the social sciences and practitioners working on HIV care with children and youth in sub-Saharan Africa. The conference was titled 'Growing up with HIV in Africa' and brought together over 50 researchers and practitioners, covering multiple disciplines, practitioner roles and issues - all of which point to the need of moving beyond a focus on virus detection, suppression and management to recognize the broader Social Determinants of Health as they relate to children living with HIV in subSaharan Africa. This Special Issue in Children and Youth Services Review presents some of the conference papers and other solicited articles on this topic. We review the contributions with the aim of mapping out and developing a model of the Social Determinants of Health as they relate to children and youth living with HIV, arguing that such a focus is timely and forces us to radically rethink current models of health care for children and youth living with HIV in sub-Saharan Africa.

\section{Conceptual frameworks}

As illustrated by the papers included in this Issue, a number of theoretical and conceptual perspectives lend themselves well to the study of children's lived experiences of growing up with HIV. These perspectives reflect the disciplines of the authors as well as the 'centeredness' and focus of the respective studies. In this Introduction we would like to focus on two conceptual frameworks that, when combined, provide us with a lens to examine and illuminate the papers as a collective.

\subsection{Social Determinants of Health}

The 1986 Ottawa Charter for Health Promotion presented a turning point for the field of public health, declaring that health is determined by, and a contributor to, political, economic, social, cultural, environmental, behavioral and biological factors. The charter emphasized that people cannot achieve their fullest health potential if they are unable to take control of those social factors that shape their health, including the distribution of resources, power and social position (Marmot \& Wilkinson, 2005). Over the years, and accelerated by the 2011 World Conference on Social Determinants of Health in Rio de Janeiro, the World Health Organization (WHO), through its Commission on Social Determinants of Health (SDH), have identified and focused their work on nine themes that contain major determinants of health. These include: employment conditions, social exclusion, priority public health conditions, woman and gender equity, early child development, globalization, health systems, measurement and evidence and urbanization.

Through highlighting how social factors moderate and determine clinical HIV care outcomes, the papers included in this Issue call for a broader vision in responding to the lived and social realities of children and youth living with HIV, rendering the SDH perspective particularly relevant. The papers therefore support a growing recognition that the health of children and adolescents, perhaps more than any other group, is largely determined by factors that lie outside of the healthservice system (Viner et al., 2012). While access to medical treatment is clearly vital to health, the SDH perspective enables us to examine how social ecological contexts shape the health and developmental wellbeing of children and youth growing up with HIV. This includes examining the material, relational, institutional and symbolic dimensions of children's social environment (Campbell \& Cornish, 2010; Skovdal, Campbell, Nhongo, Nyamukapa, \& Gregson, 2011).

The SDH perspective, firmly embedded into the public health discourse by commentators such as Marmot (2005), and Dahlgren and Whitehead (1991), has received much interest and continues to guide much public health work around the world. However, a criticism of the SDH perspective is that it is notoriously difficult to operationalize through policy and practice (Exworthy, 2008), partly because it calls for a holistic and inter-sectoral approach to public health, breaking down siloed responses. Given these challenges, we seek to unpack the SDH perspective by tailoring it to a particular context and population, namely children and youth living with HIV in sub-Saharan Africa. In other words, we want to use the SDH perspective to map out the Social Determinants of Health as they relate to children and youth living with HIV.

\subsection{Therapeutic citizenship}

Central to most of the papers in this Issue is the notion that being HIV positive is life changing, experienced through biological and social changes (henceforth, biosocial changes). For example, HIV seroconversion detected in children and youth sets in motion an apparatus of clinical HIV care, which requires children and their caregivers to adopt certain practices, sparking modifications to their lives centered around the project of children becoming 'therapeutic citizens'. Growing up with HIV effectively becomes a journey of adaptation, which inevitably shifts individual notions of self and other. The term 'therapeutic citizenship' was coined by Nguyen (2005: 126), to describe "a biopolitical citizenship, a system of claims and ethical projects that arise out of the conjugation of techniques used to govern populations and manage individual bodies." In other words, and in the context of HIV, therapeutic citizenship refers to the responsibilities and rights of people living with HIV to access HIV services (Nguyen, Ako, Niamba, Sylla, \& Tiendrebeogo, 2007). With roots in biopolitics and 'biological citizenship' (cf. Petryna, 2003; Rose \& Novas, 2005), much research guided by the notion of therapeutic citizenship explores the interfaces between patient identities, clinical care, and the political economy.

By using these two conceptual frameworks of SDH and therapeutic citizenship in concert, we open up for the possibility of exploring how children's abilities to manage their HIV status and treatment, becoming therapeutic citizens, are determined by an array of biological, psychological and social drivers. Collectively, the frameworks provide us with a lens to explore how we can best facilitate health-enabling 
social/structural environments that better support children and youth living with HIV, their families and health services to manage the interface between biosocial changes and treatment outcomes.

\section{Social Determinants of Health as they relate to children and youth living with HIV}

Documenting the experiences and responses of children and youth living with HIV, their caregivers and HIV service providers, the articles in this Issue, albeit to different degrees and in different ways, point to the need of a broader vision of HIV care, a vision that encourages us to go beyond clinical virus detection, suppression and management. This is particularly well illustrated by Mburu et al. (2014) who approached their interview data from a social-ecological perspective, illustrating how adolescents' experiences of living with HIV are influenced by individual-, family- and peer-, community- and structural level factors. To further unpack the components of this vision, we thematically analyzed the papers, deriving eight themes that we argue form the Social Determinants of Health as they relate to children and youth living with HIV in sub-Saharan Africa (see Fig. 1 for a summary). We now discuss these themes in turn.

\subsection{Health services}

It is evident through all the articles that health services are central to the lived experiences of children and youth living with HIV. Many of the articles emphasize the need to equip health facilities to better respond to the unique needs and experiences of children and youth living with HIV, making them more attractive, child- and youth friendly. One area of focus in a number of the articles pertains to HIV disclosure. Disclosure of HIV status to a seroconverted child is a milestone in the continuum of HIV care and in framing children's experiences of HIV, but also notoriously difficult for health service providers to 'get right' given children's different social experiences and developmental progression. Mattes (2014a), for example, in an ethnographic enquiry into the experiences of children and youth on antiretroviral therapy in Tanzania, found children to receive inconsistent information about their health status. He also found health staff to be too busy to engage with the unique needs and experiences of children and adolescents - resorting to an authoritarian style of communication and disease management. Similar observations were made by Kajubi et al. (2014) in Uganda and by Class (2014) in Mozambique, with Class (2014) further noting trust and communication issues arising between children's parents and health staff.

Practitioners across sub-Saharan Africa recognize these challenges and are actively looking to make HIV services more child and youth friendly, but often do so with limited resources and evidence-base. Lowenthal et al. (2014), describing a comprehensive clinic-based disclosure support program in Botswana, present their experiences of developing, implementing and scaling up a disclosure model that through work with the entire family, enables children to gradually learn about their illness, matching their psychosocial maturation. Similarly, Strasser and Gibbons (2014), describe how the Elizabeth Glaser Pediatric AIDS Foundation in Zambia has incrementally developed psychosocial support services for children and youth living with HIV using a "learning by doing" approach, constantly innovating and building on lessons learned. Reflecting on six psychosocial programs, ranging from teen mentoring activities and play therapy to equipping counselors with the skills to communicate with and counsel children and youth, they (ibid.) exemplify how busy health practitioners need to think 'out of the box' and actively develop solutions that consider the complex needs of children and youth.

There is growing emphasis on community-based and outreach services. However, as observed by Busza et al. (2014), in their study of a home-based care program in Tanzania, such services, like clinic-based services, also need to be tailored to reflect the lived experiences and expectations of adolescents. Making outreach and clinic-based services child and youth friendly does make a difference. This is illustrated by
Black et al. (2014) who report on an integrated youth center model, where health clinic services, educational and leadership initiatives were brought together and incorporated into a rewards program, where points earned from use of youth center services, including HIV testing, could be translated into gift vouchers. The authors found that compared to standard HIV services in the local community, the youth center model contributed to increased HIV testing behaviors amongst the $12-15$ year old age group in the targeting community (ibid.). Community-based and outreach services, as well as incentives systems, may go some way to overcome some of the demand-side barriers that Schenk et al. (2014), in Kenya, found to impede uptake of HIV services amongst children and youth. These community barriers included reliance on traditional healers, stigma and associated costs related to treatment amongst others.

These studies highlight a number of important issues. Disclosure cannot be considered a quick and one-time event. Disclosure should form part of a process that is developmentally appropriate and done in collaboration with the children's family. Relatedly, the studies suggest we cannot merely adopt HIV service models initially designed for adults. We need to engage children, youth and their families in creative ways and develop HIV services that take into consideration the lived experiences and social realities of children and youth.

\subsection{Family and kinship}

Children's development depends hugely on having a nurturing family or home environment (Sherr et al., 2014). For children and youth living with HIV, this includes the active participation of caregivers as therapeutic partners. The mediating role of families in children's treatment and experience of HIV is highlighted particularly well in two of the articles of this Issue. Sikstrom (2014) for example, drawing on two years of ethnographic fieldwork following a group of HIV positive children accessing services from a rural health clinic in Malawi, show how everyday social relationships within households shape long term treatment success for children. Amongst other things, she demonstrates children's dependence on primary caregivers as treatment partners, but also highlights complexity, pointing out that from her observations in Malawi, a father's participation in a child's therapy management group is more likely to impede, rather than promote, early HIV diagnosis and treatment initiation for children.

In Uganda, Kajubi et al. (2014), also through ethnographic work, examined HIV positive children's communication about their health and medicine in treatment centers, post-test club meetings and at home. Within the family, Kajubi et al. (2014) observed a silence about HIV, even where disclosure had taken place. While caregivers would ask the children if they had taken their medicines, children had few opportunities to discuss the sickness itself and the implications of HIV on their health and future. Although some children adopted a strategy of continually asking their caregivers about their medicines and illness, or simply talked to other people, this lack of open communication about the children's illness is worrying and undermines children's ability to manage biosocial changes. Similar observations were made in Zambia and South Africa by Mburu et al. (2014) and Vujovic et al. (2014) respectively. However, as also noted by Vujovic et al. (2014), certain topics, like sexual and reproductive health, are taboo and cannot easily be addressed within the family (ibid.).

These studies underline the importance of adopting a family perspective in the provision of HIV services to children and youth. They highlight the need to integrate family-centered approaches into the continuum of HIV care, involving caregivers as treatment partners and equipping them with the communication skills required to provide children and youth living with HIV the kind of support they may need.

\subsection{Poverty and economic resources}

Poverty undoubtedly makes it more difficult for children and youth living with HIV, as well as their caregivers, to manage their health and 


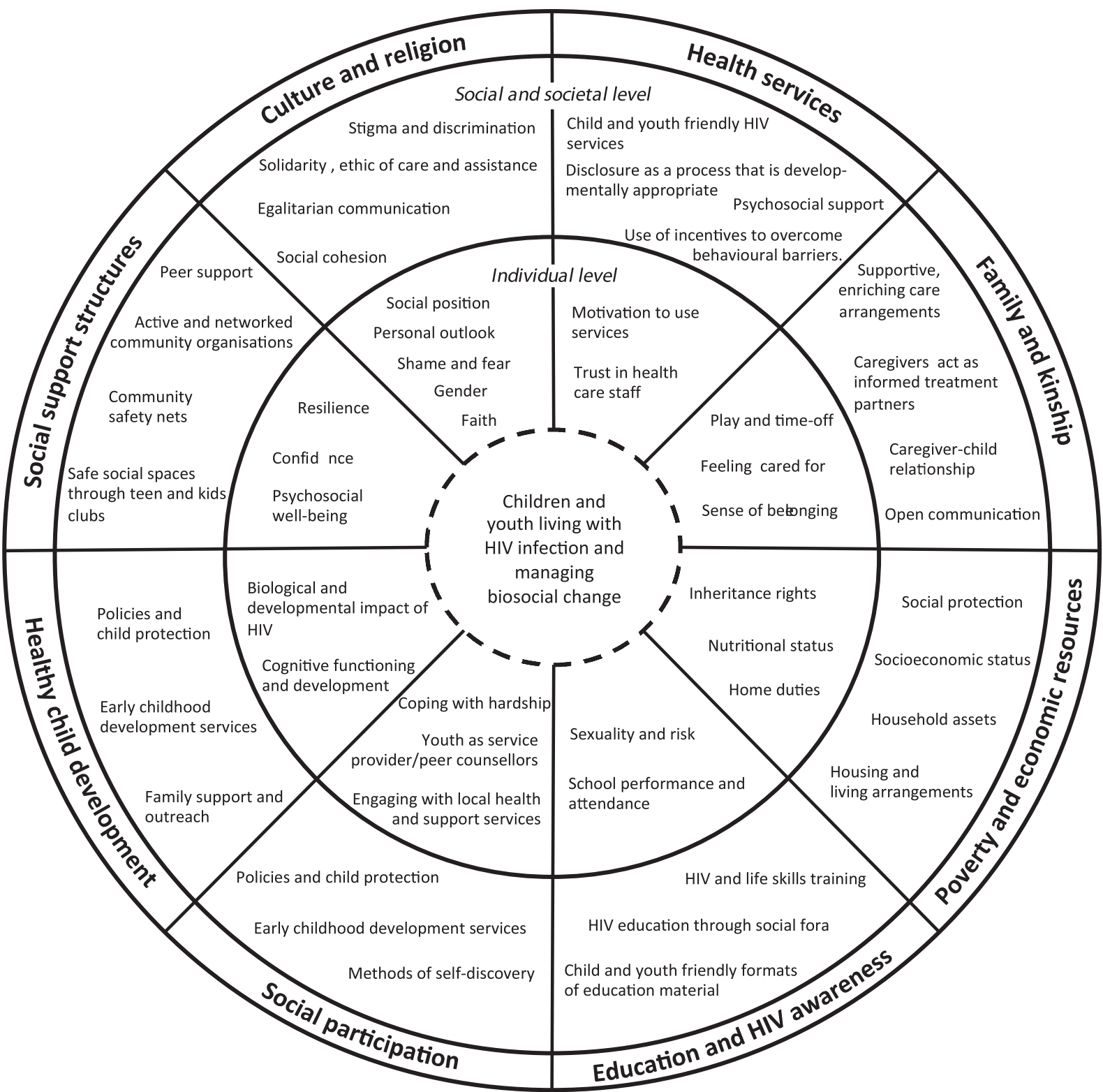

Fig. 1. Social Determinants of Health as they relate to children and youth living with HIV infection.

psychosocial well-being. Sikstrom (2014) for example discusses how many of the families in her study struggled to provide children on ART with a diet that sustains the efficacy of their treatment. The combination of poverty, a lack of awareness of nutritious and locally available foods and limited social networks, seemed to exacerbate this challenge. In Zimbabwe and Kenya respectively, Mupambireyi et al. (2014) and Schenk et al. (2014) found treatment related costs, including transport and nutritional demands, to be a significant barrier to children's uptake of HIV services.

Equally, a number of papers alluded to the protective role of economic and material resources. Fournier et al. (2014) for example show how having access to household assets, such as livestock and land for farming, as well as decent housing, provide poor and HIVinfected children with a sense of protection and security. This suggests that there is a need to integrate social protection programs that fight poverty in HIV-affected households into the health system, and to enable health staff to enroll or refer children and youth living with HIV onto such a program.

\subsection{Education and HIV awareness}

The association between education and health is well known, with a growing and persistent evidence-base. Although formal education equips children and youth with the literacy skills and competencies needed to assimilate and navigate much HIV information, a number of papers call for more creative and developmentally appropriate formats of HIV education. In relation to engaging adolescents living with HIV, Vujovic et al. (2014) map out a variety of challenges pertaining to adolescents' ability to act as active agents in maintaining their sexual and reproductive health. This includes accessing age- and gender appropriate HIV information, as well as obtaining sexual and reproductive health and life skills that enable them to deal with stigma and discrimination; experiences of loss; a negative future orientation; fears of illness and death and relationship concerns. Vujovic et al. (2014) used this study to develop a manual, aimed at helping service providers build solid and positive foundations for the future sexual and reproductive health of young adolescents in their care. 
Snyder et al. (2014), also in South Africa and responding to the HIV and sexual and reproductive health information needs of adolescents, report on a curriculum incorporating both didactic, interactive and youthoriented cognitive behavioral tools that can facilitate self-awareness, social support, and healthy behavior change. They found that applying these tools in a structured and short-term support group setting provides newly diagnosed HIV positive youth with an effective entry point for long-term HIV wellness and care. Mupambireyi et al. (2014) also report on the benefits of providing HIV education in social forums.

\subsection{Social participation}

Children and youth are not merely passive recipients of HIV treatment, care and support. Although dependent on each individual child's abilities and developmental stage, many children and youth play an active role in sustaining their health by engaging with health-enabling actors in their social environment (Skovdal \& Daniel, 2012). This is illustrated in many of the articles, for example through their participation in teen and kids' clubs (Mupambireyi et al., 2014) and by persistently seeking information about their illness from caregivers (Kajubi et al., 2014). In addition to highlighting the limits of social participation in clinical settings, manifested in authoritarian communication by clinicians, Mattes (2014a) demonstrates how children and youth develop an understanding of their health condition by 'putting the pieces together'. He (ibid) also shows how children and youth take certain steps to construct a sense of normalcy as a way of coping with the devastating impact of losing a parent or dealing with stigma and discrimination. These examples not only showcase children and youth as actors in managing social and biological changes, but also demonstrate inadequacies in much current service delivery. Children and youth, for example, should not have to 'put the pieces together' or repeatedly ask their caregivers in order to develop an understanding of their health condition. Some children, particularly the young and those with reduced ability, may not be able to maneuver their social environment to the same extent, leaving them particularly disenfranchised.

Key to social participation is recognition of the different abilities of children and youth to manage biosocial change, and identifying opportunities to better engage and tailor support for children and youth. Two articles report on participatory methods where children and youth can articulate their thoughts and experiences of living with HIV. Willis et al. (2014) for example report on a pilot program in Zimbabwe using digital storytelling to facilitate a process of self-discovery, as well as contribute to an improved understanding and awareness of children's struggles and coping strategies amongst health workers and in families. They involved 12 adolescents living with HIV who through short and emotive films narrated their experiences of living with HIV. Related to social participation, some of the adolescents described joining a support group to be a key turning point in their lives, particularly as they began to take on a service provider role themselves (as peer counselors). Willis et al. found the digital storytelling exercise to be therapeutic to the adolescents and powerful as an advocacy tool in creating a more healthenabling context. Similarly, in Uganda, Fournier et al. (2014) explore the potential of Photovoice as a method to better understand the life experiences of orphaned and HIV positive children. Both Fournier et al. (2014) and Willis et al. (2014) found participatory methods, like Photovoice and participatory filming, to usefully illuminate strengths and protective factors in addition to their struggles, offering nuanced insights to the lives of children and youth living with HIV.

Growing up with HIV is challenging for many children and youth. They need to maneuver a number of bodily and social changes, and adopt a number of strategies to do so. As illustrated by some of the papers in this Issue, this might involve children and youth engaging with health-enabling actors in their social environment. Some of these actors are local (e.g., caregivers or health providers), while others are external (e.g., NGOs facilitating digital storytelling or researchers introducing Photovoice).

\subsection{Healthy child development}

Sherr et al. (2014) present a systematic review of research looking at the cognitive performance of children living with HIV. Their study confirms that children living with HIV are at increased risk of cognitive delay compared to their HIV negative peers. This disposition, partly determined by children's biological responses to the virus and treatment as well as social factors, such as parental responsiveness and environmental richness, cements the need for early childhood development programs and health service activities that cater for the cognitive function needs of children. The evolving literature also points to the necessity to deconstruct cognitive functioning into various domains such as language, memory, executive functioning, abstract thinking and to examine pockets of challenge as well as pockets of ability. There are a number of responses in the broader child development literature that could be adapted yet there is very little action beyond documenting problems that children face. Such a review, Sherr et al. (2014) argue, needs to translate into policy and provision where educational interventions need to be created or adapted with growing urgency.

Relatedly, Skeen et al. (2014) set out to compare the developmental outcomes of children living with HIV and children otherwise affected by HIV, for example through parental illness, and to determine the types of services they receive from community-based organizations. As most studies are confined to clinic samples, this study examines the community level impact. Corroborating the review by Sherr et al. (2014), children living with HIV were more likely to have developmental difficulties, further predicted by living with a sick family member and not attending school regularly. Despite being in greater need, they also found children living with HIV to be comparatively less likely to participate in early child development and educational support programs offered by community organizations.

These two studies highlight an urgent need for interventions offering child development services aimed at children and youth living with HIV. They suggest that health services, including communitybased programming, need to be sensitive to the individual developmental needs of children and youth living with HIV.

\subsection{Social support structures}

Social support structures, whether formal groups or informal networks, play an instrumental role in the HIV response (Gregson et al., 2013; Skovdal et al., 2013). A number of articles included in this Issue speak to the role of support groups in aiding HIV treatment, care and support of children and youth living with HIV (e.g., Strasser and Gibbons, 2014; Lowenthal et al., 2014; Mupambireyi et al., 2014; Kajubi et al., 2014). Vujovic et al. (2014) propose a group approach to addressing sexual and reproductive health issues. In Zimbabwe, Mupambireyi et al. (2014) found children to speak of support groups as safe social spaces. The children spoke of the support groups as spaces to identify role models and to restore confidence, both in themselves and in their future The support groups also served as a vehicle for health workers to offer guidance and support around medication and adherence, as well as to provide children with an opportunity to spend time with peers in similar circumstances and gain a sense of normalcy. (ibid). Similar observations were made by Mburu et al. (2014) in Zambia, where peers who were also living with HIV featured prominently as a source of psychosocial support and friendship. Gitau et al. found peer support to offer adolescents with rich social exchanges that make them feel valued and better prepared at managing biosocial changes.

Other social support structures mentioned in the articles include community-based organizations (Skeen et al., 2014), group homes (Fournier et al. 2014), peer support (Mburu et al., 2014) and drop in-style youth centers (Black et al., 2014). Also, the lack of social support featured in a number of articles. This was often manifested in HIV-related stigma and discrimination (Fournier et al., 2014), and further supports the need to address the impact of negative social 
settings on the health and well-being of children and youth living with HIV.

\subsection{Culture and religion}

Culture and religion, encompassing customs and social representations, shape the beliefs and patterns of human behavior that characterize a social milieu. It is in social milieus where health promotion messages are translated and where social cohesion is nurtured shaping our lived experiences and the way we conduct ourselves. Drawing on research conducted in Mozambique, Class (2014) offers one example of how standard HIV prevention messages are interpreted in a cultural context and how this in turn impacts pediatric treatmentseeking and adherence to treatment. She found HIV prevention messages to propagate HIV-related fear and shame, which, mediated by a mix of stigma, perceived reliability and accessibility of HIV information and trust in health workers, was reported to have a negative impact on caregivers' engagement with HIV services.

Whereas certain religious practices may at times be counterproductive to people's adherence to biomedical treatment regimes (e.g. Mattes, 2014b), Mattes (2014a) showed that religion can also serve as an instrumental source of confidence for children and youth living with HIV who are struggling go maintain their sense of normalcy and a positive future orientation.

Also the studies by Kajubi et al. (2014) and Mattes (2014a) exemplify the mediating role of social milieus in facilitating health-enabling contexts. They highlight how children's disenfranchised social position influences adult-child communication in ways that obstruct children and youth from becoming therapeutic citizens. Sikstrom (2014) draws attention to how gendered social dynamics may impede timely initiation of testing and treatment. She gives the example of a woman who, despite suspecting that her newborn son is HIV positive, was unable to get him tested until she obtained consent from her husband.

Through a review of articles included in this Issue, we have discussed emerging themes that shed light on eight Social Determinants of Health as they relate to children and youth living with HIV. We have in Fig. 1 summarized these social determinants, illustrating how they operate on both individual and social levels and serve as a pathway to help children and youth living with HIV manage biosocial changes.

\section{Concluding comments}

It is evident from the articles in this Issue that social/structural milieus shape the ability of children and youth living with HIV to manage biosocial changes. Building on previous calls for addressing social drivers of HIV (e.g., Auerbach, Parkhurst, \& Cáceres, 2011; Seeley et al., 2012) and adolescent health (Patton et al., 2014), the articles firmly cement the need to understand and better respond to the social conditions that govern the health and well-being of children and youth growing up with HIV. Children's disenfranchised position and gender inequalities, manifested in social and cultural norms, and actioned through social relationships with adults (e.g., caregivers and health workers), shape their experiences of living with HIV. Poverty has a profound effect on the ability of children, their families and health services to adequately respond to their treatment needs and HIV-related stigma and discrimination often contributes to social isolation and poor psychosocial health.

As most of the articles draw on children's experiences of growing up with HIV, we also gain an insight to their role in managing their illness, and struggles to become therapeutic citizens. With an emphasis on how children and youth actively navigate their social environments to sustain their health, many of the articles suggest that therapeutic citizenship should not merely refer to the responsibility of the individual patient and as a means to govern populations (Nguyen et al., 2007), but reminds us of our responsibility to facilitate social environments that enable HIV-affected families, including children and youth themselves, to maintain their right to health, act as therapeutic citizens, and broadening the focus to include both clinic and community at the very least. The SDH perspective that emerges from the articles of this Issue (See Fig. 1), helps us get a little closer to understanding what such a social environment might look like.

A focus on families is particularly important given that not all children, particularly the young and those with reduced ability, have equal access to opportunities to exercise agency and participate in the management of their health. Moreover, and as discussed earlier, parents and caregivers play a key role in mediating the experiences of children and youth living with HIV. A growing body of evidence suggests that reorganizing facilitybased services around family outreach activities can have a positive impact on HIV outcomes (Betancourt, Abrams, McBain, \& Fawzi, 2010; Rochat, Bland, Coovadia, Stein, \& Newell, 2011; Wright \& Leahey, 2013). Such specialized provision is needed with corresponding training and competence requirements for providers.

It is not enough, however, to map out the social and cultural norms, structures and institutional factors at local levels that shape the health and well-being of children and youth living with HIV in Africa. We need to take heed of the findings presented in this Issue and develop interventions that address various aspects of the SDH perspective and nurture synergies and inter-sectoral responses. This might include integrating psychosocial support programs into clinical care or establishing partnerships and referral systems, so that clinicians, for instance, can sign up poor and HIV-infected children for social protection schemes. It is our hope that a SDH perspective can offer practitioners a framework to develop and refine local programming to enhance service delivery for children and their families, so that they are better equipped to negotiate the complex biological and social changes that HIV has presented them with.

Needless to say, taking a holistic approach comes at a cost, requires political commitments and a rethinking of how aid funding and scarce resources are distributed and managed. As we discuss in the concluding paper of this Issue (cf. Belton and Skovdal 2014), the current UNAIDS "Getting to Zero" global policy mandate for 2011-15 offers a prime opportunity to advocate for political commitments to increase the adoption of the SDH perspective.

To conclude, we have mapped out the contextual influences that govern the health and well-being of children and youth living with HIV in sub-Saharan Africa, developing a SDH perspective that is tailored to the needs of children and youth growing up with HIV. We hope to offer researchers and practitioners with a framework to further develop this conceptual perspective and advocate for a more holistic vision of HIV care for children and youth living with HIV. It is our conviction that such a framework has the potential to improve HIV treatment outcomes and the ability of HIV-affected families, including children themselves, to better manage biosocial changes by cementing the need to i) understand, measure and respond to drivers of health, health inequities as well as developmental challenges; ii) foster partnerships and inter-sectoral cooperation; iii) adopt family- and community-centered approaches that are linked to broader care and support systems and iv) to develop a focused research agenda on Social Determinants of Health as they relate to children and youth living with HIV. Only then can the promise of an AIDS-free generation become, not just a promise, but a reality.

\section{Acknowledgments}

We would like to thank all the contributors of this Special Issue for their active participation in the conference and preparation of manuscripts. Thanks also to the Annual Fund of the London School of Economics and Political Science for funding the 'Growing up with HIV in Africa' conference. Special thanks go to Imara Ajani Rolston and Rochelle Burgess for their editorial support of this Special Issue. Opinions or points of view expressed in this article are those of the authors and do not necessarily reflect the official position or policies of Save the Children. 


\section{References}

Auerbach, J.D., Parkhurst, J. O., \& Cáceres, C. F. (2011). Addressing social drivers of HIV/ AIDS for the long-term response: conceptual and methodological considerations. Global Public Health, 6, S293-S309.

Barth, R. E., Tempelman, H. A., Smelt, E., Wensing, A.M. J., Hoepelman, A. I., \& Geelen, S. P. (2011). Long-term outcome of children receiving antiretroviral treatment in rural South Africa: substantial virologic failure on first-line treatment. The Pediatric Infectious Disease Journal, http://dx.doi.org/10.1097/INF.0b013e3181ed2af3 (Publish Ahead of Print).

Belton Sara, \& Skovdal Morten (2014). 'Getting to Zero': The policy role of social determinants of health as they relate to children and youth living with HIV in sub-Saharan Africa. Children and Youth Services Review, Available online 4 April 2014, ISSN 01907409, http://dx.doi.org/10.1016/j.childyouth.2014.03.043.

Betancourt, T., Abrams, E., McBain, R., \& Fawzi, M. (2010). Family-centred approaches to the prevention of mother to child transmission of HIV. Journal of the International AIDS Society, 13, 1-11.

Black Samantha, Wallace Melissa, Middelkoop Keren, Robbertze Dante, Bennie Thola Wood Robin, \& Bekker Linda-Gail (2014). Improving HIV testing amongst adolescents through an integrated Youth Centre rewards program: Insights from South Africa. Children and Youth Services Review, Available online 4 April 2014, ISSN 0190 7409, http://dx.doi.org/10.1016/j.childyouth.2014.03.025.

Braitstein, P., Songok, J., Vreeman, R. C., Wools-Kaloustian, K. K., Koskei, P., Walusuna, L. et al. (2011). "Wamepotea" (they have become lost): outcomes of HIV-positive and HIV-exposed children lost to follow-up from a large HIV treatment program in Western Kenya. JAIDS Journal of Acquired Immune Deficiency Syndromes, 57, e40-e46, http://dx.doi.org/10.1097/QAI.0b013e3182167f0d.

Busza Joanna, Besana Giulia, V. R., Mapunda Pasiens, \& Elizabeth Oliveras (2014). Meeting the needs of adolescents living with HIV through Home Based Care: Lessons learned from Tanzania. Children and Youth Services Review, Available online 5 April 2014, ISSN 0190-7409, http://dx.doi.org/10.1016/j.childyouth.2014.03.030.

Campbell, C., \& Cornish, F. (2010). Towards a 'fourth generation' of approaches to HIV/ AIDS management: creating contexts for effective community mobilisation. AIDS Care, 22.

Campbell, C., Scott, K., Nhamo, M., Nyamukapa, C., Madanhire, C., Skovdal, M., et al (2013). Social capital and HIV competent communities: the role of community groups in managing HIV/AIDS in rural Zimbabwe. AIDS Care, 25, S114-S122.

Campbell, C., Skovdal, M., Mupambireyi, Z., Madanhire, C., Nyamukapa, C., \& Gregson, S. (2012). Building adherence-competent communities: factors promoting children's adherence to anti-retroviral HIV/AIDS treatment in rural Zimbabwe. Health \& Place, $18,123-131$.

Class Deena (2014). Effects of HIV Prevention Messages on Treatment-Seeking and Adherence for HIV-Infected Children in Maputo, Mozambique: A qualitative study. Children and Youth Services Review, Available online 4 April 2014, ISSN 0190-7409, http://dx.doi.org/10.1016/j.childyouth.2014.03.039.

Dahlgren, G., \& Whitehead, M. (1991). Policies and Strategies to Promote Social Equity in Health. Stockholm: Institute for Future Studies.

Exworthy, M. (2008). Policy to tackle the social determinants of health: using conceptual models to understand the policy process. Health Policy and Planning, $23,318-327$.

Fournier Bonnie, Bridge Andrea, Kennedy Andrea Pritchard, Alibhai Arif, \& Konde-Lule Joseph (2014). Hear our voices: A Photovoice project with children who are orphaned and living with HIV in a Ugandan group home. Children and Youth Services Review, Available online 4 April 2014, ISSN 0190-7409, http://dx.doi.org/10.1016/j. childyouth.2014.03.038.

Gregson, S., Nyamukapa, C., Schumacher, C., Magutshwa-Zitha, S., Skovdal, M., Yekeye, R. et al. (2013). Evidence for a contribution of the community response to HIV decline in eastern Zimbabwe? AIDS Care, 25, S88-S96.

Kajubi Phoebe, Bagger Stine, Katahoire Anne, R., Kyaddondo David, \& Whyte Susan, R. (2014). Spaces for talking: Communication patterns of Children on Antiretrovira Therapy in Uganda. Children and Youth Services Review, Available online 4 April 2014, ISSN 0190-7409, http://dx.doi.org/10.1016/j.childyouth.2014.03.036.

Lowenthal Elizabeth, D., Jibril Haruna, B., Belton Sara, Sechele Mmapula, L., Mathuba Keofentse, \& Tshume Ontibile (2014). Disclosure of HIV Status to HIV-infected Children in a Large African Treatment Center: Lessons Learned in Botswana. Children and Youth Services Review, Available online 5 April 2014, ISSN 0190-7409, http://dx. doi.org/10.1016/j.childyouth.2014.03.031.

Marmot, M. (2005). Social determinants of health inequalities. The Lancet, 365, 1099-1104

Marmot, M., \& Wilkinson, R. (2005). Social Determinants of Health. Oxford: Oxford University Press.

Mattes Dominik (2014a). "Life is not a rehearsal, it's a performance": An ethnographic enquiry into the subjectivities of children and adolescents living with antiretroviral treatment in northeastern Tanzania. Children and Youth Services Review Available online 5 April 2014, ISSN 0190-7409, http://dx.doi.org/10.1016/j.childyouth.2014.03.033.

Mattes, D. (2014b). The blood of Jesus and CD4 counts: dreaming, developing and navigating therapeutic options for curing HIV/ADIS in Tanzania. In R. Van Dijk, H. Dilger, M. Burchardt, \& T. Rasing (Eds.), Saving Souls, Prolonging Lives: Religion and the Challenges of AIDS-Treatment in Africa. London: Ashgate (forthcoming).

Mburu Gitau, Ram Mala, Oxenham Danielle, Haamujompa Choolwe, Iorpenda Kate, \& Ferguson Laura (2014). Responding to adolescents living with HIV in Zambia: A social-ecological approach. Children and Youth Services Review, Available online 5 April 2014, ISSN 0190-7409, http://dx.doi.org/10.1016/j.childyouth.2014.03.033.

McNairy, M. L., Lamb, M. R., Carter, R. J., Fayorsey, R., Tene, G., Mutabazi, V., et al. (2013) Retention of HIV-infected children on antiretroviral treatment in HIV Care and treatment programs in Kenya, Mozambique, Rwanda, and Tanzania. JAIDS Journal of
Acquired Immune Deficiency Syndromes, 62, e70-e81, http://dx doi.org/10.1097/QAI. Ob013e318278bcb0

Mugglin, C., Wandeler, G., Estill, J., Egger, M., Bender, N., Davies, M., et al. (2013). Retention in care of HIV-infected children from HIV test to start of antiretroviral therapy: systematic review. PLoS ONE, 8, e56446.

Mupambireyi Zivai, Bernays Sarah, Bernays Sarah, Bwakura-Dangarembizi Mutsa, Bwakura-Dangarembizi Mutsa, \& Cowan Frances, M. (2014). "I don't feel shy because I will be among others who are just like me..." The role of support groups for children perinatally infectedwith HIV in Zimbabwe. Children and Youth Services Review, Available online 5 April 2014, ISSN 0190-7409, http://dx.doi.org/10.1016/j.childyouth. 2014.03.026.

Nguyen, V. (2005). Antiretroviral globalism, biopolitics, and therapeutic citizenship. In A. Ong, \& S. Collier (Eds.), Global Assemblages: Technology, Politics, and Ethics as Anthropological Problems (pp. 124-144). Malden, MA: Blackwell Publishing.

Nguyen, V., Ako, C., Niamba, P., Sylla, A., \& Tiendrebeogo, I. (2007). Adherence as therapeutic citizenship: impact of the history of access to antiretroviral drugs on adherence to treatment. AIDS, 21, 31-35

Patton, G., Ross, D., Santelli, J., Sawyer, S., Viner, R., \& Kleinert, S. (2014). Next steps for adolescent health: a Lancet Commission. The Lancet, 383, 385-386.

Petryna, A. (2003). Life Exposed: Biological Citizens after Chernobyl. Princeton: Princeton University Press.

Rochat, T. J., Bland, R., Coovadia, H., Stein, A., \& Newell, M. -L. (2011). Towards a family-centered approach to HIV treatment and care for HIV-exposed children, their mothers and their families in poorly resourced settings. Future Virology, 6, 687-696.

Rose, N., \& Novas, C. (2005). Biological citizenship. In A. Ong, \& S. Collier (Eds.), Global Assemblages: Technology, Politics, and Ethics as Anthropological Problems (pp. 439-463). Oxford: Blackwell Publishing.

Schenk Katie, D., Kiragu Karusa, Murugi Julie, \& Sarna Avina (2014). If you build it, will they come? A qualitative investigation into community barriers to accessing paediatric HIV services in Kenya. Children and Youth Services Review, Available online 5 April 2014, ISSN 0190-7409, http://dx.doi.org/10.1016/j.childyouth.2014.03.034.

Schwartländer, B., Stover, J., Hallett, T., Atun, R., Avila, C., Gouws, E., et al. (2011). Towards an improved investment approach for an effective response to HIV/AIDS. The Lancet, 377, 2031-2041.

Seeley, J., Watts, C. H., Kippax, S., Russell, S., Heise, L., \& Whiteside, A. (2012). Addressing the Structural Drivers of HIV: A Luxury or Necessity for Programmes.

Sherr Lorraine, Croome Natasha, Castaneda Katherine Parra, Bradshaw Katie, \& Romero Rocio Herrero (2014). Developmental challenges in HIV infected children - an updated systematic review. Children and Youth Services Review, Available online 4 April 2014, ISSN 0190-7409, http://dx.doi.org/10.1016/j.childyouth.2014.03.040.

Silva-Santisteban, A., Segura, E., Sandoval, C., Giron, M., Petrera, M., \& Caceres, C. (2013). Determinants of unequal HIV care access among people living with HIV in Peru. Globalization and Health, 9, 22

Sikstrom Laura (2014). "Without the grandparents, life is difficult": Social hierarchy and therapeutic trajectories for children living with HIV in rural Northern Malawi. Children and Youth Services Review, Available online 4 April 2014, ISSN 0190-7409, http://dx.doi.org/10.1016/j.childyouth.2014.03.037.

Skeen Sarah, Tomlinson Mark, Macedo Ana, Miltz Ada, Croome Natasha, \& Sherr Lorraine (2014). Child development in HIV positive and HIV affected children in South Africa and Malawi - what role for community organisations? Children and Youth Services Review, Available online 4 April 2014, ISSN 0190-7409, http://dx.doi.org/10.1016/j. childyouth.2014.03.041.

Skovdal, M., Campbell, C., Madanhire, C., Nyamukapa, C., \& Gregson, S. (2011). Challenges faced by elderly guardians in sustaining the adherence to antiretroviral therapy in HIV-infected children in Zimbabwe. AIDS Care, 23, 957-964.

Skovdal, M., Campbell, C., Nhongo, K., Nyamukapa, C., \& Gregson, S. (2011). Contextual and psychosocial influences on antiretroviral therapy adherence in rural Zimbabwe: towards a systematic framework for programme planners. The International Journal of Health Planning and Management, 26, 296-318.

Skovdal, M., \& Daniel, M. (2012). Resilience through participation and coping-enabling social environments: the case of HIV-affected children in Africa. African Journal of AIDS Research, 11, 153-164.

Skovdal, M., Magutshwa-Zitha, S., Campbell, C., Nyamukapa, C., \& Gregson, S. (2013). Community groups as 'critical enablers' of the HIV response in Zimbabwe. BMC Health Services Research, 13, 195

Snyder Kate, Wallace Melissa, Duby Zoe, Aquino Lisa, D. H., Stafford Stephen, Hosek Sybil, Futterman Donna, \& Bekker Linda-Gail (2014). Preliminary Results from Hlanganani (Coming Together): A structured support group for HIV-infected adolescents piloted in Cape Town, South Africa. Children and Youth Services Review Available online 5 April 2014, ISSN 0190-7409, http://dx.doi.org/10.1016/j.childyouth.2014.03.027.

Strasser Susan, Skovdal Morten, \& Gibbons Sue (2014). The development of HIV-related mental health and psychosocial services for children and adolescents in Zambia: The case for learning by doing. Children and Youth Services Review, Available online 5 April 2014, ISSN 0190-7409, http://dx.doi.org/10.1016/j.childyouth.2014.03.032.

Tene, G., Lahuerta, M., Teasdale, C., Mugisha, V., Kayonde, L., Muhayimpundu, R., et al. (2013). High retention among HIV-infected children in Rwanda during scale-up and decentralization of HIV care and treatment programs, 2004 to 2010. The Pediatric Infectious Disease Journal, 32, e341-e347, http://dx.doi.org/10.1097/INF. 0b013e31828c2744.

Tolle, M.A., Phelps, B. R., Desmond, C., Sugandhi, N., Omeogu, C., Jamieson, D., et al. (2013). Delivering pediatric HIV care in resource-limited settings: cost considerations in an expanded response. AIDS, 27, S179-S186, http://dx.doi.org/10.1097/QAD. 0000000000000105.

UNAIDS (2013). Global Report: UNAIDS Report on the Global AIDS Epidemic 2013. : Joint United Nations Programme on HIV/AIDS (UNAIDS). 
UNICEF (2013). Towards an AIDS-Free Generation - Children and AIDS: Sixth Stocktaking Report. New York: United Nations Children's Fund.

Viner, R., Ozer, E., Denny, S., Marmot, M., Resnick, M., Fatusi, A., et al. (2012). Adolescence and the social determinants of health. The Lancet, 379, 1641-1652.

Vujovic Marnie, Struthers Helen, Meyersfeld Saranne, Dlamini Kgethi, Mabizela Nhlanhla, \& Cowan, F. (2014). Addressing the sexual and reproductive health needs of young adolescents living with HIV in South Africa. Children and Youth Services Review, Available online 5 April 2014, ISSN 0190-7409, http://dx doi.org/10.1016/j.childyouth 2014.03.028.

Wachira, J., Middlestadt, S. E., Vreeman, R., \& Braitstein, P. (2012). Factors underlying taking a child to HIV care: implications for reducing loss to follow-up among
HIV-infected and -exposed children. SAHARA-J: Journal of Social Aspects of HIV/AIDS, 9, 20-29.

WHO, UNICEF, \& UNAIDS (2013). Global Update on HIV Treatment 2013: Results, Impact and Opportunities. Geneva: World Health Organisation.

Willis, N., Frewin, L., Miller, A., Dziwa, C., Mavhu, W., \& Cowan, F. (2014). “My Story” - HIV positive adolescents tell their story through film. Children and Youth Services Review Available online 5 April 2014, ISSN 0190-7409, http://dx.doi.org/10.1016/j. childyouth.2014.03.029.

Wright, L., \& Leahey, M. (2013). Nurses and Families: A Guide to Family Assessment and Intervention. Philadelphia: FA Davis. 